\title{
Business Analytics for Managing Performance of Microfinance Institutions: A Flexible Management of the Implementation Process
}

\author{
Isabelle Piot-Lepetit ${ }^{1, *(D)}$ and Joseph Nzongang ${ }^{2}$ (D) \\ 1 Montpellier Interdisciplinary Center on Sustainable Agri-Food Systems-Social and Nutritional Sciences, \\ National Research Institute for Agriculture, Food and Environment, University of Montpellier, \\ 34000 Montpellier, France \\ 2 CERME (Centre d'Etudes et de Recherche en Management et Economie), Faculty of Economics and \\ Management, University of Dschang, Dschang, Cameroon; jonzongang@gmail.com \\ * Correspondence: isabelle.piot-lepetit@inrae.fr
}

check for updates

Citation: Piot-Lepetit, I.;

Nzongang, J. Business Analytics for Managing Performance of

Microfinance Institutions: A Flexible Management of the Implementation Process. Sustainability 2021, 13, 4882. https://doi.org/10.3390/su13094882

Academic Editor: Jean-Pierre Gueyie

Received: 16 March 2021

Accepted: 16 April 2021

Published: 27 April 2021

Publisher's Note: MDPI stays neutral with regard to jurisdictional claims in published maps and institutional affiliations.

Copyright: (c) 2021 by the authors. Licensee MDPI, Basel, Switzerland. This article is an open access article distributed under the terms and conditions of the Creative Commons Attribution (CC BY) license (https:/ / creativecommons.org/licenses/by/ $4.0 /)$.

\begin{abstract}
Microfinance institutions are social enterprises that focus on the provision of financial services to poor populations excluded from the conventional banking system. These organizations face a double-bottom line, dealing simultaneously with a financial and social objective. The challenge of putting it into action is great, especially when there is a need to involve all stakeholders and to replicate the experience to new communities. One way to sustain both financial performance and social impacts is to develop a business analytics solution aiming at measuring and expanding social impacts in a financially sustainable way. This paper describes main elements to be considered, in particular the organizational context, the development process, and implementation issues that would facilitate or impede the deployment of a business analytics initiative in practice. Finally, two main components of the implementation process are specifically pointed out: a behavioral fit of the business analytics solution to the cultural context of the organization, and the country where it is deployed, and a flexible commitment in the management of the business analytics initiative implementation.
\end{abstract}

Keywords: business analytics; decision-making; efficiency measurement; financial performance; social impact; data envelopment analysis; developing countries; microfinance; social enterprises

\section{Introduction}

Social enterprises provide structures that people trust and help them escape the poverty trap and gain control over their lives. They most often combine traditional entrepreneurship with a mission focusing on basic human needs that existing markets and institutions have failed to satisfy. Thus, social enterprises have developed new business models with, as a common feature, a social mission most often not provided by current economic and social institutions. Indeed, those enterprises are designed on local needs and not on assumptions, supported by large institutions, about what should to be done. Moreover, the creation of social value is the primary and main objective of their development; the creation of economic value being often only based on an objective of financial sustainability and operational self-sufficiency. Most often, they depend on funds provided by foundations for their launching and the beginning of their activity, until their activity can generate sufficient revenues to cover at least their operating costs [1]. Social enterprises cover a large range of services that are failing the poor, such as health, education, mobile telephony, or bank loans. In particular, microfinance institutions (MFIs) are social enterprises offering financial services to low- and very low-income populations, which do not have access to the conventional financial system. The main financial services offered are loans, savings, and insurance. The lack of access to loans by poor people results from the fact that they cannot put up acceptable collateral. For banks, the costs of screening, monitoring the activities of the poor, and enforcing their contracts are too high to make 
lending to them profitable [2]. Lack of access to credit is considered one of the main reasons why many people remain poor. However, poor people have ideas they cannot develop as well as skills they cannot deployed, mainly because of a lack of financial support [1]. Thus, the social objective of MFIs is the granting of micro-credits to micro-entrepreneurs to help them in the financing of self-employment projects or the launching and development of very-small and small-sized enterprises. Promoting microenterprises, especially in developing countries, is, generally speaking, justified in their abilities to foster economic growth, alleviate poverty, and generate employment. As the strategic objectives of MFIs are financially self-sufficient and targeting poor people excluded from the conventional banking system, they face a 'double bottom-line' [3], and a trade-off may exist between both objectives for these institutions [4].

Our case study focuses on the Mutuelles Communautaires de Croissance (or $\mathrm{MC}^{2}$ ) that offer financial services through a network of village banks in order to improve living conditions of targeted communities. They focus on promoting agriculture, rural development, and job creation in rural Cameroon [5]. Despite more than a decade of economic growth, poverty in Cameroon was still at $37.5 \%$ in 2014, corresponding to 8.3 million people, with more than $90 \%$ in rural areas and $69 \%$ of all poor people located in the north of the country [6]. Launched in 1992, the $\mathrm{MC}^{2}$ network has grown throughout the country and now contains more than 70 village banks. The business model of these village banks is a development in four phases that includes: (i) sensitizing the poor population, (ii) mobilizing resources, especially through micro-savings, (iii) financing individual income generating activities, and (iv) promoting community projects having an objective of job creation. As the $\mathrm{MC}^{2}$ network expands and invests in a new activity (community projects), an assessment of the performance and sustainability of the network and its village banks was thought as a critical step helping at identifying their strengths and weaknesses as well as areas where improvements are needed. Indeed, those MFIs are independent non-profit entities sharing the same business model, functioning, organizational structure, and name. As the network has become more mature with more individual entities and several stages of development, managing them only based on experience and instinct and without a data-driven solution supporting decision-making can become a limiting factor to its development and a potentially misleading way of moving forward. Thus, a business analytics solution was thought and developed with four main objectives: (1) assessing the performance of the network and its entities on a regular basis [7], (2) providing time-dependent guidance aiming to improving performance to managers, both locally and at the network level, (3) identifying village banks able to start the granting of loans to collective projects [8], and (4) understanding the 2008 global financial crisis impact on the activities of the network and its village banks [9]. This latter analysis was thought as critically important to understand how they have passed the shock and thus identify their competitive advantage within the microfinance sector. Indeed, they were able to maintain their activity, while at the same time facing an increase in their members of $36 \%$, with $66 \%$ more poor people within their client portfolio, as well as an expansion of their micro-credit activity of $80 \%$ over the 2008-2012 period.

Business analytics (BA) is a discipline or "a category of computing rather than a specific method, application, or product" [10] (p. 11). BA is transforming how decisions are being made and managed in various organizations. It allows managers to no longer work only on experience, instinct, or intuition, but to use data and facts to support their decision-making and improve their operations. Through the synergistic use of multiple analytical approaches on the same data set, BA supports a management built upon logic and evidence [11]. Initiated by the need to either address specific problems or explore and learn from existing data, the primary purpose remains improving the way organizations do business as well as driving better business decisions [12]. However, information alone is of limited value, until they can be leveraged and become managerial actions, e.g., improvement of operational decisions, redesign or modification of existing processes, and formulation or adjustment of strategies. As stated by Liberatore and Luo. [13] (p. 314), 
"[Analytics] is a process of transforming data into actions through the analysis and insights in the context of organizational decision-making and problem solving". For transforming BA into actionable outcomes, it is of critical importance that practitioners understand both business needs and the analysis performed on data, and then develop a data-driven decision-making culture [11]. By leveraging existing data, BA gives decision-makers the ability to discover more insights than with other managerial approaches and enables them to gain a holistic view of their business. BA helps identify business successes and failures, align business goals and actions, monitor progress, and develop new strategies [14]. Moreover, the maturity of industries or organizations can increase the need of supporting the implementation of BA initiatives, so as to reduce the cognitive effort required to perform a decision-making task by reducing the range of possibilities to be investigated and leading to cost savings [15].

The objective of this paper is to describe the basis for the development of a business analytics solution in the context of Microfinance as well as main elements to be considered when dealing with social enterprises in a context of poverty. Following recommendations of Ranyard et al. [16] (p. 11), details regarding the organizational context, the development process, and implementation issues that could facilitate as well as impede the deployment of the solution in practice are described and discussed. The paper is organized as follows. Section 2 sets main challenges, drivers, and processes to be considered when developing a BA solution in such a specific context, here a network of village banks in Cameroon. Section 3 specifies the types of business analytics to be implemented. Section 4 deals with the selection of a relevant methodology for doing so. Section 5 puts forward two main elements to be considered when working in a context of poverty in developing countries, while Section 6 concludes.

\section{Main Challenges, Drivers and Processes}

Understanding business decision-making based on available data is becoming a crucial challenge for organizations. However, to make an optimal use of data collected and stored on a regular basis, companies need to take a number of actions that are, among others, to find the right focus, build the right culture, hire the right people, and install the right technology [17]. Indeed, the top three big challenges identified by SAS (cited in Bayrak [14]) are: (i) lack of skills and expertise, (ii) difficulty in accessing data, and (iii) not effectively using most valuable data to make decisions. For Clark and Wiesenfeld [18], the three main obstacles that can prevent the realization of the full value of analytics are all related to people and not to technology. As pointed out by Ranyard et al. [16], barriers to adoption of a solution are client resistance, cost of the solution, data limitation, and staff lacking expertise; with the former being the most important aspect. Client resistance is especially relevant when the organization does not have enough awareness and understanding of the analytics solution. Thus, developing tools closely aligned with organizational problems is of the upmost importance. Following the classification in four main driving forces of Liberatore and Luo [13], which are data, software, process, and people and the three main obstacles of Clark and Wiesenfeld [18], which are the organizational structure, culture, and approach to problem-solving, we describe main issues that could be encountered and choices that should be made regarding the design and development of the analytics solution for the $\mathrm{MC}^{2}$ network in Cameroon.

\subsection{Data Collection and Auditing}

A business analytics begins with data collection, extraction, and cleaning. Organizations collect and store internal (or even external) data for many purposes, e.g., record keeping and regulatory compliance. However, without correct data, analyses are either impossible or can lead to erroneous conclusions [13]. Access to high quality and structured data is of the most critical importance, when leveraged to improve decision-making and business outcomes. So, for analytics initiatives, data and information become a 'strategic asset' $^{\prime}[10]$ (p. 12), on which appropriate analyses can be implemented. Data quality issues 
can be considered at the time of gathering data, organizing them in a format ready for analyses, extracting, transforming and rearranging data for performing these analyses, or at the time of the model creation process. This activity is however the most critical phase of an analytical solution.

In the specific case of the $\mathrm{MC}^{2}$ network, data are collected on a regularly basis by extension service staff of the non-governmental organization called ADAF (Appropriate Development for Africa Foundation) that provides support for capability building, staff training, and accounting procedures to network managers. ADAF staff make regular visits to village banks and provide help for specific issues. At the same time, they collect and audit data before transferring them to relevant stakeholders as well as the regulatory authority: COBAC (Commission Bancaire de l'Afrique Centrale). Thus, audited data are available on spreadsheet at the executive secretariat of the network and are updated on a yearly basis. Thus, while Lustig et al. [10] considered that BA solutions respond to a need of business agility of decision-makers, i.e., the possibility to bring real-time decisions regarding both people and processes, it is important to point out that in a context of poverty dealing with village banks located in rural Cameroon, the concept of time and reactivity has to be rethought. However, the availability of reliable data on a regular timeframe as well as on a IT support is a valuable asset that can be looked at as a stepping stone for a business analytics initiative.

\subsection{The Culture of the Organization}

Senior managers' understanding and attitudes towards a BA solution are a critical element to consider in order to take advantage of its full potential and benefit [16]. The approval and support of senior managers are of the utmost importance for developing a culture within the organization, where such a solution can be deployed and used for better insights into business issues and opportunities as well as for guiding operational managers in their daily activities in accordance with their mission and in line with the strategy of the organization as a whole.

In the specific case of the $\mathrm{MC}^{2}$ network, the first step was to illustrate the relevance and reliability of the BA solution suggested to improve the performance of the network as a whole and of each village bank. To illustrate the usefulness and potentiality of the recommended approach, a feasibility study was first implemented. A sample containing accounting data for 20 villages banks having more than 10 years in operation in 2006 (30\% of the $\mathrm{MC}^{2}$ network units, located at $70 \%$ in the same region) was provided. Then, a basic model was developed using available information and implemented, so as to illustrate the type of results provided by the BA solution, their benefits for the organization as well as improvements to be considered to gain a better overview of the network performance [19]. Based on this first implementation of a basic BA solution, a second study was launched, based on all village banks with more than 5 years of operation in 2009. These 52 MFIs, working without subsidies, were studied with as an objective gaining a deeper understanding of areas where performance improvements were needed [20]. Even though results were found interesting and trustable, their presentation was considered as too complicated to be used by the managers of the network and village banks. Thus, the third step was to think about a way of translating results coming out of the modeling part of our BA solution in concepts daily used by them, with as an objective reducing at the minimal the disruption between current practices and new information provided by the BA solution [7]. This latter step is of a critical importance for the acceptability of the BA solution by managers and to open doors for a new phase of the implementation process that is: defining an organizational structure in which to embed the solution within the MC ${ }^{2}$ network.

Concerning the culture of organizations, Clark and Wiesenfeld [18] pointed out that they can make counterproductive decisions when they are too data-driven. At the contrary, they may resist adjusting, even when data clearly indicate it is relevant to do so, when they rely too heavily on instinct. Thus, finding out a right balance between those two extremes is of the upmost importance. The translation of the BA results into key performance indica- 
tors already mastered by both network and local managers and developed by international organizations for the microfinance sector is a critical element to introduce a right distance and good level of interactions between BA analysts and BA users. Indeed, using performance monitoring indicators of the microfinance sector already known by network and village bank managers to communicate results in a format understandable by them as well as to receive feedback regarding areas where to improve the BA solution to make it easier to use is a really productive action to implement. Particularly, developing time-dependent improvement paths towards higher performance was thought as a real added-value to the BA solution facilitating both recommendations and exchanges on performance between extension service staff and village bank managers [8].

\subsection{Organizational Priorities and Processes}

A process orientation helps better understand tasks of a business model and identify where a better design involving either fundamental changes in the overall process or just adjustments of some of its elements [21] could improve performance. Furthermore, business analytics performed to improve decisions associated with the overall process or sub-processes prevents potential suboptimal choices [13]. Moreover, the process approach facilitates the identification of organizational priorities on which the modeling part of the BA solution has to focus.

In the case of the $\mathrm{MC}^{2}$ network, the activities of each village bank follow a cumulative capability development approach [22]. This approach relies on four steps: (i) make aware the community of the village bank concept; (ii) collecting resources, especially through micro-savings; (iii) granting microloans to individual income-generating activities; and (iv) financing community projects aiming for development and job creation in rural communities, where village banks are located. When they develop a new capability, they also have to maintain the performance level of previous ones; so that they can develop each component of their activity without trade-off among them. As MFIs have a dual nature [3], namely a financial and social one, a successful management of MFIs is seen as a simultaneous expansion of both components without trade-off between the objective of financial sustainability and outreach to the poor [4], together with having an impact on the welfare of populations concerned by those projects [23].

Accordingly, the microfinance activities have been specified as process and subprocesses. The overall production process concerns the provision of financial and social outputs using inputs. It is then decomposed into sub-processes using models prevalent in the banking and financial literature [24]. In the first sub-process, resources are used to provide deposits and savings, corresponding to the production approach $[25,26]$. Then, in the second sub-process, deposits and savings are used to provide financial services through an intermediation approach $[27,28]$. In doing so, the intermediate role of deposits, as either an input or an output depending on the theoretical banking production function considered, is taken into account. Finally, the overall financial process of village banks is described based on inputs from the production sub-process and outputs from the intermediation sub-process. It provides an assessment of the financial sustainability process, that is the capacity of MFIs to durably grant loans to its members. Regarding the social production process of village banks, the outputs from the financial production process are used as inputs in the provision of social outputs. Selected social outputs are those most often found in the literature: the breadth of outreach, evaluated by the number of clients, and the depth of outreach, measured by the number of women and the number of poor served. However, measuring poverty, based on available or easy to collect data, is not so obvious as it is a relative concept. The poverty indicator defined by Gutiérrez-Nieto et al. [29] was used to assess the degree of poverty of the client portfolio. Finally, the global production process of MFIs is described using the inputs and outputs from the overall financial process as well as the outputs from the social production process. This multi-process approach in three stages allows the identification of areas where improvements are needed, either in the overall production process or in some of its components [7]. 


\subsection{People and Technology}

A BA solution focuses on an entire business process, is relevant to all managers, supports many activities across an organization, and often affects decision-making [13]. Ranyard et al. [16] found in the literature that barriers to the adoption of BA solutions concern untrained management in the use of BA tools that does not sufficiently understand its benefits, due to a lack of knowledge regarding the techniques deployed in the BA solution. In their study, they identified client resistance, cost of the solution, data limitation, staff lacking expertise as important barriers, with the first one being the most important aspect. Whatever the quality of the analytical tool produced, its use, and implementation, recommendations and prescriptions are carried out by people. They are also dependent on people to turn prescriptions coming out of the solution into actions [30]. Thus, for embedding a BA solution within an organization, it is equally important to possess analytical software that helps to drive the use of analytics as analytically oriented managers or users with background in quantitative disciplines that are aware of the usefulness of making fact-based decisions. Moreover, an analytics tool is expected to be maintained and used independently of people at the origin of its development. Thus, continuity has to be thought about, so as to provide a specific structure that can endure in time, even if decision-makers present at the creation of the BA solution move to other positions [13]. Regarding the organizational structure, Clark and Wiesenfeld [18] explained that isolated analytics departments using specialized software packages and specifying complicated solutions can provide solutions far and away from business activities and difficult to understand and implement by business partners. At the opposite, analysts too deeply involved in business functions tend to provide solutions promoting the status quo or supporting leadership's thinking. Moreover, if the analytics solution is overly complex with limited adaptability, then the organization may lack infrastructure to directly implement it in its current production setting. At the contrary, too simplistic analytics solution may fail to capture all the components of the problems they are trying to solve. Thus, a right balance has to be achieved between these two extremes.

The current organizational structure of the $M C^{2}$ network is based on a communitycentered growth and development initiative. Each village bank is independent, but shares by the same name and a tri-party support arrangement, involving the Afriland First Bank and the non-governmental organization ADAF. The Afriland First Bank is a commercial bank. It provides financial assistance, plays the role of external auditor, and facilitates some banking procedures. ADAF, an NGO specialized in fighting against poverty and sustainable development, provides support for capability building, staff training, and accounting procedures. It also makes regular visits to the village banks and provides help for specific issues. Even though the data-driven solution presented in this paper aims to increase the financial and social performance of village banks, it is absolutely necessary to define a structure of implementation that minimizes resistance among members of the network. Resistance is linked to the disruption the analytical solution brings in the manner decisions are made. As explained by Luoma [15], the new organizational structure has to fit with current routine practices, with BA tools closely aligned with organizational problems and procedures, especially when the organization lacks of awareness and understanding of analytics solutions [16]. Thus, for deploying and maintaining the BA solution developed for the $\mathrm{MC}^{2}$ network, it is important to provide minimal changes in the current organizational structure. It is also necessary to overcome the issue of staff scarcity with an analytical background within the network, without providing a 'human-dependent' solution, i.e., a solution that cannot last if informed and trained staff move to another position. Finally, it was thought that an optimal option is to follow the recommendations provided by Clark and Wiesenfeld [18], concerning an effective analytics organization.

\subsection{Integration of the BA Solution within the Network Organizational Structure}

The elements of an effective analytics organization balance functional business knowledge and data analysis, with a commitment to complexity only when it is justified or impos- 
sible to do otherwise. For Clark and Wiesenfeld [18], this kind of organization includes: an analytics nerve center, a representation at the top, and a 'champion-challenger' approach.

The analytics nerve center is ideally built upon a small team of data scientists with advanced degrees in computer science, mathematics, or statistics. Members of this nerve center develop, maintain, and implement the analytics solution. They also work closely with analytics generalists located in the organization's business departments. Knowing the languages of both analytics and business, having a deep functional know-how and understanding of data analysis, these analytics generalists are able to initiate and develop actionable analyses. They also play the role of liaisons between data scientists and business partners. They rely on the nerve center for data analysis and training, but act as transmission agents. Then, the responsible of the nerve center is expected to attend meetings of senior managers and offers them information and insights coming out of the BA solution. Doing so is considered as a powerful strategy by Clark and Wiesenfeld [18], especially when analytics and instinct come together. When the two disagree, additional research conducted by the analytics nerve center is expected to identify if it comes from the modeling approach used or business assumptions of senior managers. Finally, Clark and Wiesenfeld [18] suggested to focus on a minimum viable analytics solution, called the 'champion' that covers almost all challenges faced by the organization without too much complexity. Only if all stakeholders agree on increasing complexity of the BA solution, a 'challenger' can be developed and become the new champion. This 'championchallenger' approach is considered as an optimal one, since it nearly always produces something viable.

Based on these recommendations, the organizational structure suggested for the $\mathrm{MC}^{2}$ network is based on (i) a research center on microfinance, (ii) extension service staff of ADAF, (iii) support groups for village banks, and (iv) the development of a business analytics solution in stages.

A research center on microfinance gathering together scholars, with an experience on microfinance and scientists with competences in data analysis and modeling, has been thought as an important component of the new organization. The objective of this center is to implement, maintain, and develop further current analytics tools. The most relevant location has appeared to be in the premise of a Cameroonian University, namely the University of Dschang due to existing connection with the $\mathrm{MC}^{2}$ network. Not being part of the network staff, scholars from the research center can stay more objective regarding recommendations to be provided. At the same time, they already have competences well able to connect findings from analytics to microfinance activities. Moreover, the location within a University is also considered as a major advantage to identify students interested in an internship focusing on microfinance, analytics, the provision of results to managers, or the development of additional tools to address specific requests from the network. In addition, those students can be considered as potential candidates for positions in either the network or the research center. Otherwise, the responsible of the center could work with the managers of the network on a regular basis. Main elements of interest are here the provision of insights regarding the functioning of the network, supporting managers when a new decision on which they lack experience has to be made, or suggesting potential courses of action that could be taken in order to improve specific areas. In doing so, the person in charge of the research center could become an active participant in the transfer of data-driven knowledge, aiming to reduce the number of choices based only on intuition and instinct during the decision-making process. Thus, the research center on microfinance, hosting analytical tools and scientists, can act as the 'analytics nerve center' suggested by Clark and Wiesenfeld [18], an essential element of the deployment of an effective data-driven decision-making solution. Additionally, the representation of the person in charge of this center within the executive secretariat of the $\mathrm{MC}^{2}$ network could help bring 'the voice of analytics' [18] to managers, supporting them in their decision-making by putting together analytics and instinct. 
The second element of the organizational structure deals with how results could be transmitted to local managers at the village bank level. The best way is to work with ADAF extension service staff visiting village banks on a regular basis, either for monitoring their activity or advising them on main elements relative to their development and performance. Thus, regular training of extension service staff could be organized by the research center with as objectives a better understanding of the functioning and usefulness of BA results and the development of a capacity to interpret them and explain how to put them into actions. Even though they are not expected to know how models are built and worked out, they understand their value and limits [13]. It is thus expected that they incorporate data-driven information provided to them by the research center on microfinance in their activity and advise local managers on how they could foster the performance of their village banks. As users of the BA solution, extension service staff, are expected to become involved in collecting updated data for the research center, so that new analysis can be implemented and new recommendations formulated. As thus, they act as analytics generalists or 'liaisons' [18] between the research center and BA users. Otherwise, another suggestion is the creation of support groups, gathering together local managers with extension service staff as moderator, with as an objective providing a place for sharing experience on performance improvements and know-how from those with a high performance to those needing help in some areas. It could also become a place for communicating on analytical results and receiving feedback, so as to improve and develop further analytical tools. Doing so contributes to the appropriation of the data-driven solution by all potential users within the network and facilitates its integration within the organizational structure and culture of the network.

Finally, rather than using the 'champion-challenger' approach suggested by Clark and Wiesenfeld [18], it was thought more appropriate to work in a way compatible with the cumulative capability development approach [22] of the network. Thus, as previously described, the BA solution was developed in stages.

\section{Selection of the Type of Analytics to Be Implemented}

Models based on statistics and mathematics can help manager monitor corporate performance, by measuring key metrics and managing operational data [14]. However, the modeling activity can easily become a black box when processes and results are owned by experts [31]. Making sure that the construction of the analytics solution and the ways results are communicated are as transparent and accessible as possible to non-analytical people helps mitigate this risk [15]. Thus, it is important to get in agreement with potential BA users within the organization on several elements aiming to set the boundaries of the BA solution under development. Main questions to be considered relate to the areas that need to be investigated and the type of decision-making that will be supported by business analytics, so as to be able to select best models to be developed to fulfill those needs.

\subsection{Identifying Areas of Needs}

Lustig et al. [10] identified five key areas of needs that BA solutions can answer to: (i) information access, (ii) insight, (iii) foresight, (iv) business agility, and (v) strategic adjustment. Information access is about developing models to get insights on available data that can be transmitted to managers to help them foster informed decision-making across the organization and ensure the identification of business areas that need to evolve or be improved. Then, insight is about gaining a deeper understanding of why things have happened, so as to make better decisions and enable increases in performance. Unlike insight that is leveraging past data in order to understand past events, foresight is about doing the same to predict potential future outcomes. In this case, models are used to suggest actions and decisions meeting the organization's objectives and requirements. In particular, it reduces the adjustment time to unexpected external or internal events and facilitates business agility by allowing real-time decision focusing on both personnel 
allocation and process optimization. The last area of needs identified by Lustig et al. [10] is strategic alignment by documenting preferences, priorities, objectives, and requirements driving decision-making within an organization in order to maintain homogeneity and uniformity of the organization's strategy.

For the $\mathrm{MC}^{2}$ network, four areas of needs were clearly identified. The first one deals with gaining information on the functioning of the network. Indeed, the first village bank was created at Baham, in the Western region of Cameroon, in 1992. Since then, village banks have been deployed all over the country. In 2007, the network counted 65 rural development village banks located in the 10 regions of Cameroon and owned by 78,925 members from various rural communities [8]. Nowadays, there exist more than 70 village banks, and the network has reached a development that involves new needs, new management procedures, and new organizational rules to keep growing, which can no longer only depend on intuition. Thus, gaining information to get objective insights on the network development and functioning is a prerequisite for making better decisions. The second one was leveraging past data to gain a deeper understanding of why things have happened and to suggest the best course of actions to be implemented and was thought as a very useful support for decision-makers and extension service staff. As village banks are located in rural areas and are developed around communities, cultural and ethnic considerations can highly influence the way decision-making is made. Providing roadmaps for performance improvement based on data and benchmarking is then a powerful support to reduce subjectivity in decision-making. The third area of need is strategic alignment. Indeed, it is the community that initiates the creation of a new village bank. Each $\mathrm{MC}^{2}$ is an association owned by its members. Thus, each village bank is an independent entity. So maintaining homogeneity among them is a challenge to overcome, especially due to the geographical dispersion of village banks all over the country and their remoteness in rural areas not always easy to access. Strategic alignment can be facilitated by the use of a data-driven solution. Finally, the last need identified was leveraging past data to plan the deployment of the fourth stage of the network development. Indeed, launched in 2010, this new phase focuses on the granting of loans for economic projects, aiming to create job within the communities where village banks are deployed. Data-based information is considered as providing an important support for setting up this new challenge. The objective is then to help identify strengths and weaknesses of each village bank, before starting granting fund to collective projects rather than individual ones; a major change from their current activities. After the identification of the four areas of the network needs, the type of decision-making involved for each of them has to be characterized, so that most relevant and effective analytical tools could be selected.

\subsection{Types of Decision-Making to Be Considered}

Luoma [15] explained that two main decision-making activities can be considered in BA, with very different consequences on the model-based analytics to be designed. Routine decision-making refers to established procedures developed over time within an organization, due to a repeated exposure to similar events or contexts. It is usually efficient and reliable. Use of modeling in such a situation focuses on increasing efficiency and effectiveness of decision-making, by enhancing the speed and/or accuracy of decisions to be made, especially when it is challenging human rationality. It helps organizations improve their functioning by providing suggestions making decision more objective than those relying just on experience and instinct. Moreover, it frees the decision maker for other important matters. Thus, a BA solution does not only improve decision-making quality, it also reduces time and cognitive effort involved by such a decision-making process, with saved resources being allocated to other most challenging issues. Applications of modeling in routine decision-making mainly focus on the implementation of current activities based on a high level of cognitive difficulty and/or an ad-hoc use of performance feedback [15].

However, when new situations occur, organizations engage in a problem-solving process, with a need of a response to a new situation. While when routine procedures fail, 
the organization meets the challenge of developing a new solution to a usual situation. Problem-solving enables the understanding of a specific issue, the identification of where to look at, and the exploration of potential solutions. It generally results in actions that are not part of the organization's repertoire. Indeed, it takes place in a complex, ambiguous, and uncertain environment where the type of outcomes, different actions will produce, is unclear [15]. In problem-solving processes, the main challenge is the scarcity or lack of data and experience [32]. It is often impossible to externally verify that the solution developed is valid, accurately predict events, or provide optimal suggestions. In this case, the primary benefit of a BA solution is facilitating the decision-making process, and models serve the purpose of providing a solution. Application of a problem-solving process is more justified when it is necessary to 'think outside the box' or to narrow the field of possibilities [15].

Considering the case of the $\mathrm{MC}^{2}$ network, the first three areas of needs corresponds to the improvement of routine decision-making. Indeed, the objective is to evaluate past performance of the village banks in both their financial and social activities, to suggest where improvements can be obtained by reducing inefficiency in current practices, and to provide time-dependent guidance for performance improvement to local managers. At the opposite, the last area of needs implies the deployment of a new activity within the network and the identification of village banks that are ready for granting larger loans to community projects, i.e., for investing in a more complex activity than granting microcredits to individual projects. In this case, it is a problem-solving approach that is expected, in order to facilitate decisions to be made by managers in a context of high uncertainty and complexity.

\subsection{Selection of Analytics to Be Developed}

Several analytical approaches can be used to explore data. Structured data analytics includes three categories of analyses of increasing complexity and impact: descriptive, predictive, and prescriptive analytics [10]. Descriptive analytics dives into data to uncover details and to understand the past or current events [14]. Relying on ad-hoc reporting, standard reporting, dashboards on spreadsheet, and basic statistics to summarize data in their multidimensional components analysis, descriptive analytics looks at data from different perspectives. Data visualization techniques allow the comparison of key performance measures, the identification of existing problems, and the discovery of potential causes to problems [13]. By far the most commonly used and well-understood type of analytics, descriptive analytics provides significant insights into business performance. It also enables a better monitoring and management of business processes. Even though insights provided by descriptive analytics can be useful in making decisions, it does not contain robust techniques either providing directions on what might happen in the future or suggesting decisions on what should be done next [10]. Predictive analytics aims at predicting future outcomes using past data or similar events [14]. It extensively makes use of time series data and techniques useful to detect patterns or relationships in data and extrapolate them forward in time, so as to develop models that predict business performance [10]. Once the past is understood, it is then necessary to also think about the best course of actions, given available data. Prescriptive analytics uses optimization models and provides optimal solutions based on a set of assumptions and constraints. It thus suggests what could happen and what could be the best decision path to implement, given the current organization's strategy [13]. Prescriptions recommend time-dependent actions to improve the future [30]. Prescriptive analytics is also used to support decision-making, modify actions, or assign resources, when problems involve numerous many choices or alternatives [10]

When starting to think about a BA solution for the $\mathrm{MC}^{2}$ network, the latter was already working with descriptive analytics. Indeed, data are collected on a regular basis, audited by staff at the executive secretariat, before being transferred to the regulatory agency. These data are available on spreadsheet, allowing the implementation of basic statistics and data visualization to gain an overview of the performance of the network. However, with 
the expansion of the network, this reporting can become insufficient to get a clear idea on what was or is going on at the village bank and network level regarding their financial and social performance. This support allows for checking progress or impairments in performance from one year to another or for comparing village banks according to their age or size; but it does not provide recommendations and directions for increasing performance of village banks, fostering the network development, and investing in its new phase of development that implies granting loans to larger projects at the community level.

For providing guidance on performance improvements to managers, prescriptive analytics based on optimization models, describing business processes and sub-processes and identifying the best course of actions for each of them, was considered as the most effective approach. Indeed, it can be used to find out optimal solutions that should have been observed if the financial and social activity of the network had been efficiently carried out. Then, the comparison of optimal solutions with current outcomes helps design specific recommendations and directions for improvement. Regarding the identification of entities able to entering the fourth phase of development of the network, it is necessary to develop a new approach based on optimization models as well as specific scorecards. The analytics tool developed suggests a planning of the village banks' integration into this new activity, based on their stage of development and performance [8].

While initially not considered as an option of the BA solution, predictive analytics was implemented later on, due to an unexpected event: the 2008 global financial crisis. After the recovery from the crisis, it appeared that no village bank went bankrupt. A question was then to gain insight from data, covering the 2008-2012 timeframe, in order to understand why and prepare village banks for new potential shocks. An analytical tool based on panel data was then developed and implemented on main components of the village banks' business model to identify why they were able to cope with the crisis and stay in business despite the shock [9].

\section{Selected Methodology: A Synergistically Use of Organizational Rules and Data Envelopment Analysis}

Companies running a successful BA initiative were found to have the following three characteristics [33]: (i) they have started with existing data, (ii) they have built analytics capabilities using business priorities, and (iii) they have created a business case for identifying measurable outcomes. For Basu [30], the BA solution should synergistically be developed on both business rules and an operational research (OR) approach. It allows, based on available data, the production of effective and timely recommendations. The business rules can be simple or complex, but need to be those implemented by the business processes, while OR is the scientific approach used to produce prescriptions regarding the best course of actions, with the aim of improving the organization's performance, taking into account its objectives, constraints, and actionable decision variables. The BA solution thought for the $\mathrm{MC}^{2}$ network follows this recommendation.

\subsection{Working with Business Rules}

For Lustig et al. [10], it is important to consider a holistic framework for advanced analytics that carefully defines and prioritizes key business questions, and performance management process within the organization. Then, the analytical tools developed has to leverage available data, and thus for each question in a structured and prioritized order. Consequently, the first stage for developing the BA solution thought for the $\mathrm{MC}^{2}$ network was to provide a comprehensive overview of their business model by decomposing their microfinance activities into processes and sub-processes [7]. This was done in a way of assessing the double dimension of their activity, while describing the business model in a production process format.

Financial sustainability is the primary objective of village banks, just after their launching. This is done by first sensitizing poor populations to the concept and then by mobilizing resources within a rural community where they are deployed. In order to become a member, a membership fee has to be paid (FCFA 2500: around US \$5), at least 10 shares (FCFA 
10000: around US \$20) have to be subscribed, and a minimum amount of FCFA 1000 (around US \$2) per month has to be saved. The entrance fee (membership, shares, and minimum savings) can be high for individual people. The group membership is an alternative allowed to share the weight of the access cost. The target population is not limited to the category of the poor, but rather extended to urban people originated from the community. This is justified by the will to strike the financial balance, but also by the fact that their participation is considered as a driving force and a guarantee of credibility during the two initial phases of development of a village bank: sensitization of the rural community, especially its poor members, and setting up micro-savings. They provide financial resources and participate to the life and development of the village bank. Thereby, the $\mathrm{MC}^{2}$ network adopts an open, non-exclusive approach. Moreover, national and international partners provide subventions for the launching of new village banks, with funds managed by ADAF. But it is then expected to develop an activity independent from subsidies at the end of the fifth year in operation [5].

Due to the importance of the activity of micro-savings collection in the business model of each village bank, the first business rule is described by the first sub-process identified in Section 2.3. It is based on the production approach from the literature on banking and financial institutions for which inputs (physical and financial resources) are used to process transactions that are taking deposits and savings. Then, using its deposits and savings, a village bank grants loans to its members to support individual, self-employment projects or the development of very-small enterprises. More recently, they have also started to financially support projects carried out by the rural community as a whole. Transforming financial resources collected into loans is defined as the intermediation process in the literature on banking and financial institutions. The second-sub-process considered in Section 2.3 corresponds to this second business rules. Finally, the business rule of financial sustainability is characterized by the overall financial process jointly considering the production and intermediation approaches. It provides an assessment of the financial sustainability of each village bank and its capacity to grant loans to its members, over a long timeframe. Just after becoming independent of subsidies, the main focus of the village banks is still their financial sustainability. Since it is the foundation of their ability to deploy their activity of outreach to poor people, they need to achieve a good financial performance to be able to increase their social performance.

The third business rule concerns the social activity of the village banks that aims to fight against poverty by mobilizing savings and resources within a community to help rural people become self-reliant in a sustainable manner. It has given birth to the motto of the network that is: Victory over Poverty (VP) can be achieved when the Means (M) and Competences $(\mathrm{C})$ of the Community $(\mathrm{C})$ are pooled together, or $\mathrm{VP}=\mathrm{MC}^{2}$. Thus, the social objective that is to target rural poor populations and to grant them loans can be broadly described as the use of outputs coming from the financial activity for the provision of social activity. As described in Section 2.3, three social outputs have been considered: the breadth of outreach, approached by the number of clients, and the depth of outreach, described by the number of poor served as well as the number of women that is a specific target of the network in order to fight against poverty in rural areas. Finally, the business model of these village banks is described by the global (financial and social) production process based on the three-stage model presented in Section 2.3 and allows a description of the double bottom-line of these microfinance institutions. Indeed, the process modeling first describes all the developments stages of villages banks of the $\mathrm{MC}^{2}$ network, capturing the role of intermediation activity based on micro-savings in the business model as well as the activity of poverty outreach having a positive welfare impact on poor people and that corresponds to the social mission of these village banks.

\subsection{Data Envelopment Analysis}

Luoma [15] (p. 822) explained it is desirable to have an optimization method consistent with decision-makers' assumptions and preferences about the 'real world' to produce a 
data-driven solution providing recommendations they will be interested in. Benchmarking is a well-known approach used by managers for performance improvement. It can be defined as a process of identifying, learning, adapting, and measuring outstanding practices of an organization. It seeks best-practices or uses standards to perform comparisons. The measurement of current practices against these reference points aims at providing relevant and concise information to help progress towards these goals. It can be considered that there exist three basic steps in a benchmarking process that are: (i) identifying best performers, (ii) setting benchmarking goals, and (iii) implementing best-practices [34]. The first step focuses on identifying decision-making units (DMUs) acknowledged as best performers or leaders in their industry [35]. However, their selection can be highly subjective and can influence the comparability of best performers with other DMUs in the industry. Depending on their size and scope, each DMU may have a different role model. Regarding the second step that is the setting up of benchmarking goals, DMUs measure their own efficiency by comparing their current practices to that of leaders. Even though benchmarking goals should be measurable, attainable, and actionable [35], their quantification, within multiple-input multiple-output contexts, is often not so easy to carry out. Finally, the third step of the benchmarking process concerns the implementation of best-practices and involves the definition of actions and practices to emulate leaders. Having indicators to judge progress in reaching benchmarking goals is critically important. It is expected to be an easy task, when the first two steps are scientifically conducted and benchmarking goals appropriately defined.

In the literature, several approaches, either deterministic or stochastic, have been suggested for implementing a performance assessment and identifying best-practices. DEA or Data Envelopment Analysis and DFA or Distribution Free Approach provide analysis based on a non-parametric frontier approach, while the SFA or Stochastic Frontier Approach is based on a parametric frontier approach. The choice among these models is based on different assumptions. In the case of DEA, no restrictive assumption about the technology has to be made; the minimal one being convexity. DFA do not require any distributional assumptions about efficiency. A main attraction of the SFA model is the possibility for many specifications, particularly in the case of panel data, and statistical distributions. The selection of the best approach relies, for instance, on the purpose of the study, the type of data or the technology characteristics, as well other elements that need to be considered in the analysis [36].

Data Envelopment Analysis (DEA) provides managers with an analytics approach that allows them to assess and manage the performance of either different branches or units, implement a benchmarking process, and identify best practices [37], not always visible when using other more common management methodologies. This approach has been thought as very relevant for supporting the BA solution and providing guidance to managers [34]. Moreover, the literature uses multiple approaches for implementing DEA models, based on either an input or output orientation or various returns to scale assumptions (constants, variables) [38-40]. Even though a multi-stage approach has been used $[7,41]$, as it better captures the production process approach selected here, all model orientations and returns to scale options have been implemented. Results based on the various DEA models are very close, showing a good reliability of the DEA methodology in the context of our study. Another important element to be considered, when implementing a DEA approach, is the selection of inputs and outputs entering the model. In the literature, several methodologies have been suggested for identifying most relevant variables. For instance, Eling [42] suggests the use of Spearman's rank correlation or principal component analysis. In our case, the selection was made on a participatory approach. Variables identified in the literature and allocated to processes and sub-processes were then presented to relevant actors of the project, and the most meaningful and easy-to-understand variables by managers were kept for our study. This participatory approach, which does not rely on strong statistical methodologies, has the main advantage to foster the potential adoption 
of the BA solution, through a contribution to the construction of the analytical tool under development at its very beginning.

Even though DEA calculations are intensive, the overall approach is straightforward. DEA essentially looks at how different inputs have been or are being used to produce different outputs. By combining information, DEA allows the comparison of different decision-making units by looking at how efficient they are at transforming inputs into outputs. In doing so, DEA provides unique insights about opportunities to improve performance [15]. Indeed, DEA produces a best-practice frontier built upon the set of best performing decision-making units (DMUs) that can then serve as role models, and look at as the industry leaders. Hence, the first step of benchmarking is achieved. Depending on their characteristics (size and scope), less performing DMUs receive a specific set of bestperformers, so that role models for a small DMU may be different from those for a large DMU. The distance between a DMU and the efficiency frontier provides the benchmarking goal, a measurable, attainable, and actionable goal, as required by the second step of the benchmarking process. Regarding the third step that is providing effective guidance to transform prescriptions into actions, a specific approach, called the DEA-Operating Frontiers (DEA-OF) model and described in the subsequent section, has been designed and implemented.

Following recommendations of Basu [30], the BA solution thought for the $\mathrm{MC}^{2}$ network synergistically uses both business rules and the operational research (OR) approach. Indeed, DEA is an OR technique using linear programming techniques [43,44] and business rules organized into processes and sub-processes, as described in previous sections, provide us with the definition of inputs and outputs entering the DEA models of our data-driven solution. Based on available data and the organization's priorities, Piot-Lepetit and Nzongang [7] evaluated the financial and social performance of the $\mathrm{MC}^{2}$ network in its multi-components, with as an objective, allowing managers to monitor and manage their operations in a more efficient way. Especially, suggestions were made in two main directions: improving efficiency and working without trade-off in the provision of financial and social services to poor people. This latter point is especially important for maintaining alignment of local managers with initial missions, as villages banks are independent entities sharing the same name.

\subsection{Defining Time-Dependent Course of Actions}

Even though insights provided by implementing DEA models on business rules organized in processes and sub-processes were highly informative, a critical extension that was thought necessary to support the transformation of recommendations into action is the design of effective guidance to managers, with suggestions of relevant and implementable courses of actions supporting decision-making, planned in time and using available data.

To answer this request, the DEA-Operating Frontiers (DEA-OF) model was created for identifying the operating environments under which each village bank undertakes its activity and then specifying performance improvement paths, thought as a step-by-step movement towards the DEA frontier [8]. DEA-OF is not connected to DDEA, the Dynamic Data Envelopment Analysis model [45]. DDEA is designed to measure the performance of a multi-period systems, with quasi-fixed inputs or intermediate products transferred between consecutive periods. DEA-OF [8] aims at identifying the various performance levels of the DMUs under investigation and providing recommendations for improvements from the lowest to the highest performance frontier or Operating Frontier. As some entities can be far away from the best-practice frontier, step-by-step recommendations are provided, focusing on performance fostering, which can be planned over a relevant time period. This extension of the traditional DEA model provides information on the best course of actions aiming at fostering the efficiency of current operations. Improvement paths are derived from available data, business rules, and the theory of performance frontiers of Schmenner and Swink [46] coming from the operations management literature. The theory of performance frontiers is based on the rationality of each manager and implies that his 
current performance describes an optimal choice, taking account into constraints coming from his current productive environment and stage of development. Two types of frontiers can be considered: (i) the asset frontier resulting from structural choices made by an organization through its investment (plants or equipment) and (ii) operating frontiers that are designed by operating management choices at a plant level; choices that are constrained by the organization's structural choices. Moreover, Schmennner and Swink [46] defined performance improvements as a movement towards higher operating frontiers, created by a simultaneously increase in all performance dimensions. This definition is a very close to the way DEA assesses DMUs' efficiency. Thus, a performance improvement path is defined as a step-by-step movement towards the best-practice frontier, with as many steps as operating frontiers above each observation's current operating frontier.

More formally, the first DEA-OF frontier corresponds to the traditional DEA bestpractice frontier. After the removal of all observations located on the first DEA-OF frontier from the sample, the second DEA-OF frontier is obtained, by running the same DEA model on remaining DMUs. Then, subsequent DEA-OF frontiers are created running the same DEA model on DMUs that have not been identified as best-performers in the previous stages. The process stops when each DMU has been positioned on one of the operating frontiers. Afterward, an improvement path can be defined as a sequence of goals towards the first DEA-OF frontier, through all the DEA-OF frontiers above each DMU's current DEA-OF frontier. This approach allows the definition of a gradual roadmap with achievable and actionable goals and is considered as very useful for implementing a step-by-step improvement of performance [47], with each step being planned in time. Thus, DEA-OF can be used to define time-dependent courses of actions that allow village banks to improve simultaneously their financial and social performance. In doing so, it also satisfies the requirement of the third step of benchmarking, which involves the definition of actions to emulate best-practices.

\subsection{Transferring Results to Final Users}

An additional challenge was the integration of this data-driven information within the network organization in a way that minimizes the disruption effect; effect resulting from the introduction of a new decision-making solution to which the managers are not unaccustomed to yet [15]. DEA results were first provided to managers in a format of dashboards based on indicators defined by international regulatory agencies for microfinance institutions [48,49] and a social scorecard developed by Woller [50].

Due to the growing importance of supporting financial viability and sustainability of MFIs, a consensus group gathering together microfinance rating agencies, donors, multilateral banks, and private voluntary organizations agreed on guidelines. Defining financial terms, ratios, and adjustments for microfinance, the set of performance indicators proposed by CGAP [48] falls into four categories: sustainability/profitability, financial management, portfolio quality, and efficiency and productivity. However, there is by no means a general agreement on how to define and calculate these performance indicators, even though many of them have become standardized. For instance, Microrate [49] uses a different list of ratios, even though some of them are identical, to assess the performance of MFIs organized into six categories: portfolio quality, efficiency and productivity, financial management, profitability, productivity, and others. These financial ratios aiming to help the evaluation of financial and management performance derive from the financial ratio analysis implemented in conventional banking and financial institutions. By revealing strengths and weaknesses, these ratios can be used as a guide to focus resources and upgrade management practices. More recently, the evaluation of microfinance activities tries to go beyond the simple promotion of financial self-sufficiency by also promoting the achievement of social objectives. New ratios have been proposed that take into account the double bottom-line of MFIs. Schreiner [51] identified six important aspects of outreach to the poor: worth to clients, cost to clients, breadth, depth, length and, scope, while Woller [50] added a seventh aspect that is outreach to community. The worth to clients is 
the value clients place on products and services provided by MFIs. The cost to clients is the sum of expenses and transaction costs for a loan application. The breadth of outreach is the number of clients. The depth of outreach is the poverty status of clients. The length of outreach is the timeframe of the supply of products and services. The scope of outreach is the number of products and services offers to clients. The outreach to community means MFI's interactions and relationships with internal and external stakeholders.

Using these financial and non-financial indicators for facilitating the transfer of DEA results to the $\mathrm{MC}^{2}$ network by means of dashboards on spreadsheet is considered as a powerful means of communication to managers. However, the first version provided was based on more than 20 performance indicators presenting results of each of the five DEA models describing the business model of village banks [7] but was found too complicated. Then, smaller and simpler dashboards were designed, allowing an easier communication of new knowledge throughout the network. Still based on financial and non-financial indicators, new indicators provide a more comprehensive description of the village bank missions, as recommended by Woller [50], but this time they are organized through three different and interrelated scorecards. These new dashboards provide information coming from DEA models using either a three-dimensional, six-dimensional, or more detailed format [52].

These key financial and non-financial performance indicators were selected based on data availability in the bookkeeping and common management practices. It provided us with 10 basic indicators. However, the scorecards were designed in a way that allows a manager to freely add to his own preferred indicators to this minimal set, through a dashboard that is easy to update and available on spreadsheet. These indicators are then distributed into six items corresponding to the six aspects of outreach defined by Schreiner [51], This scorecard provides a broad view of the social benefit of microfinance. Finally, the six dimensions of this social scorecard are reduced into the three perspectives describing the triangle of microfinance [23]. The latter considers the simultaneous expansion of financial sustainability, outreach to the poor, and welfare impact, as a successful management of microfinance institutions. Thus, the scorecard can be looked at in various dimensions and synthetic ways by either managers, practitioners or international organizations working with the microfinance sector. The financial sustainability dimension of the triangle includes the length and scope of outreach, the outreach to the poor dimension groups the breadth and depth of outreach, and the welfare impact dimension looks at how poverty is reduced and people and communities are changed and corresponds to the worth and cost to clients. Moreover, the seventh aspect identified by Woller [50] of outreach to community will be added at a later stage, when more data on the activity of financing collective projects are available. These three new scorecards are linked to each other and are updated when a value is changed in one of them [8].

\subsection{External Validation of the Business Analytics Solution}

External validity is important in evaluating models used to support routine decisionmaking [53]. It gives the possibility to rigorously test the validity of the model's assumptions by comparing recommendations coming out of the model with actual patterns of decisions [15]. Thus, an experimentation on a sample of village banks was thought as a critical step before deploying the BA solution. This test phase, aiming to verify the adequacy of the results provided by the BA solution to a sample of village banks agreeing to voluntarily follow up directions provided for performance improvement, was considered as useful for evaluating the impact of the BA prescriptions on the village banks and also comparing them with village banks located on similar DEA-OF frontiers, but not selected for implementing performance improvements coming out of the BA solution. As it was not possible to implement this test, an alternative option has been investigated. As no village bank went bankrupt between 2008 and 2012, it was thought interesting to gain insights on what happened during this timeframe, since data were continuously collected over the 
period by the $\mathrm{MC}^{2}$ network. Moreover, it was also considered as a way to assess how far our prescriptions were from what was actually observed during the period.

An intertemporal multi-DEA approach was implemented. This work was carried out by using a Malmquist productivity index [54] and its decomposition into various sub-indexes. Evaluated by means of the DEA approach, in order to identify (i) changes in the operating efficiency and frontier of the $\mathrm{MC}^{2}$ network and its village banks during the period as well as (ii) changes in its scale efficiency and the mix of resources used and outputs produced, these indexes allow an investigation of the persistence of performance over time. Results clearly showed that the operating and scale efficiency of the network and its village banks was maintained all over the period, at the exception of the intermediation activity, i.e., the transformation of micro-savings into micro-credits. The efficiency of the latter was improved in both the management and the size of the activity. Over the studied period, the intermediation function has been expanded and was in 2012 at a higher level than that observed in 2008. Information that points out that intermediation is the core activity of the $\mathrm{MC}^{2}$ network and its competitive advantage within the microfinance sector [9]. Thus, the analytical tool implemented here can be used on a regular basis to monitor performance of the core activity of the network that is intermediation, on which its sustainability is built upon and to maintain it at a high level. Moreover, it was found that increases in outputs suggested by our DEA models were almost all the time largely below what has been observed over the 2008-2012 period [8]. Thus, our prescriptions can be considered as achievable and actionable, and these comparisons can be used as an illustration on how they can really help foster performance of each village bank.

As pointed out by Basu [30], as business processes evolve over time, the BA solution has to continually re-prescribe, so that recommendations remain relevant. It implies recalculations with new data arrival or after a specific event. Nowadays, our recommendations based on data for year 2008-2012 are no longer relevant. The use of more recent data describing the new productive environment of the village banks of the $\mathrm{MC}^{2}$ network is now necessary to provide up-to-date prescriptions.

\section{Implementing an Analytics Solution for Microfinance Institutions: Two Main Elements}

\subsection{The Behavioral Fit of the Analytics Solution to the Cultural Diversity of the Country}

The 'behavioral fit' [15] (p. 824) of a data-driven solution refers to the extent by which modeling disrupts established decision-making procedures. It influences the adoption of the BA solution by practitioners. Some actors may resist formally or informally to the BA solution, and by thus they can undermine the performance of the organization. This can be mitigated when the construction of the analytical tools and the communication of the results are made as transparent and accessible as possible to non-modelers. The appropriateness of the BA solution heavily depends on the problem addressed and organizational and environmental factors. If the BA solution and results highly fit with current behaviors, it will minimize the disruption, introduced by the solution, in the manner decisions are made. Minimizing this disruption is important, since it may generate conflict within the organization [15].

The organization for which the BA solution was developed is located in Cameroon. Even though a positive economic growth has been observed over the past decade, poverty remains an uncovered challenge for this country and has become a rural phenomenon over years. In 2014, poverty was at $37.5 \%$, i.e., 8.3 million people among which $90 \%$ live in rural areas and $69 \%$ in the North regions [6]. More specifically, poverty decreased from $40 \%$ in 2001 to $38 \%$ in 2014, but with a declined in urban areas from 18\% in 2001 to $9 \%$ in 2014 and an increase in rural areas from 52\% in 2001 to $57 \%$ in 2014 [55]. The low impact of growth on poverty reduction in Cameroon mainly comes from a growing inequality. Indeed, the Gini index increased from 42.8 in 2007 to 46.6 in 2014 [6]. Moreover, Cameroon is a country with a relatively skilled population and qualified administration [55]. However, most of educated people are either in the administration of the country or in cities and big towns. Thus, to find out people that can become BA analysts or developers, it is important to 
establish the 'analytics nerve center' [18], close to potential candidates for such positions. That is why the research center on microfinance located in the premises of a Cameroonian University has been considered as a suitable option for hosting the BA solution. The University of Dschang is located in West Cameroon at about $425 \mathrm{~km}$ northwest of Yaoundé, the capital of the country, where the executive secretariat of the $\mathrm{MC}^{2}$ network is located.

Otherwise, Cameroon is located in Central and West Africa and hosts around 250 African native languages together with two official languages that are English and French, a reminder of its colonial history. Populations located in rural Cameroon not always speak official languages, and thus, communicating to them may become a challenge [56]. Moreover, in each rural community, the power of traditional authorities is still high, and customary rules can take precedence over official ones [57]. Based on these facts, staff from extension services of the $\mathrm{MC}^{2}$ network can integrate this functioning in their activity. Indeed, each village bank belongs to its community members. Thus, respecting customary rules of the community and speaking its native language, if possible, are of a critical importance for communication purposes and dissemination of the network strategy. Especially, it is necessary to present changes involved by the BA solution that will be used for supporting decision-making of village bank managers in a way that can be understood and accepted by traditional authorities of the community. The objective here is to reduce at the minimum explicit or implicit resistance to these changes within the community. To contribute to the acceptability of the change in how basic routine decisions are made, as required by the implementation of the BA solution, results from the feasibility studies realized at the very beginning of the project or results from the impact of the 2008 global financial crisis on the network and village banks can be mobilized as communication supports to illustrate the usefulness and reliability of the BA solution. Furthermore, an emphasis is put on the fact that using such prescriptions for decision-making frees up time and cognitive efforts of managers that can be dedicated to more social activities, especially regarding poor people and community projects.

In case of strong resistance from the community to such a change, the research center on microfinance could support extension service staff in their communication process by providing additional results to village banks' managers and members on specific requests, so as to reduce at the minimum the disruption involved by the BA solution. However, Basu [30] adequately pointed out that if the prescription is ignored, it would be, at some point, collected in the incoming data, and subsequently included in the upcoming recommendations. In addition to that, the creation of support groups for facilitating the implementation of prescriptions coming out of the BA solution has been suggested. Groups can be built upon the results of the DEA-OF model. Indeed, this model provides a clustering of the village banks into operating frontiers, i.e., entities sharing the same operations level as well as similar objectives in terms of performance improvements. However, before setting up those groups, knowledge of each rural community has to be integrated, so as to put together actors without any ethnic conflict and, if possible, sharing the same native language or a close cultural background. As explicitly pointed out by Basu [30], it is necessary to consider the 'action-ability' of prescriptions and supports organizations in doing so.

\subsection{A Commitment to the Analytics Solution Implementation through a Flexible Management}

A commitment to a particular strategy is the prerequisite to sustained superior performance in most competitive situations, while flexibility to change is the ability to adapt to or take advantage of uncertainty. As explained by Ghemawat and del Sol [58], it is a key to success in turbulent times. A flexible management involves the adjustment of the planned course of actions based on information received about it and its postponement or abandonment when it becomes impossible to take agreed actions. The possibility of adapting a planned course of actions is valuable, since most often few commitments take place exactly as expected. That is why, it is really important to manage the commitment 
in a flexible way. In this context, committing in several stages, instead of all at once, with the possibility of abandoning still remaining, makes flexibility an interesting option [58], especially when implementing a business analytics solution.

For the $\mathrm{MC}^{2}$ network, a flexible management of commitment involves adaptations of the course of actions over time, as defined by the DEA-OF model. It is really important to consider any specific feedback or information about unexpected events that can impede the planned roadmap. This possibility is thought as highly valuable, especially in a context of poverty where uncertainty is frequent and insecurity related to conflicts or climatic hazard has to be taken into account. Accordingly, the step-by-step improvement paths provided by DEA-OF can be used to identify various stages of commitment, avoiding the trap of a commitment all at once. Indeed, at each step of an improvement path, a flexible management means adjusting the course of actions based on new information obtained. At the extreme, it involves a provisional stopping of the implementation for village banks facing tough time. As pointed out by Ghemawat and del Sol [58], adaptation makes all the difference between success and failure. That is why it is a critical element to be taken into account when implementing a data-driven solution. Our recommendation is thus that extension service staff first present DEA-OF results to local managers, collect information on their relevance, and then adjust them in accordance with their current productive environment or postpone the implementation until unusual events have been resolved (e.g., bad weather conditions, armed conflicts, or important changes in the financial resources of the village bank). When necessary, it can be envisioned to re-run DEA models for adjusting recommendations to new and unexpected environmental conditions. Before launching the implementation process, an agreement between extension service staff, local managers, and, if necessary, the board of directors of the village bank should be obtained, so that actions aiming to increase performance can start. Even though the BA objectives are reduced during the discussion process aiming at establishing the agreement, the most important thing is to start the implementation, so as to push forward both the financial and social performance of these village banks. That is why it is highly recommended to stay flexible when being committed to the implementation of a BA solution.

\section{Conclusions}

Based on an experience of development of a business analytics (BA) solution for a network of village banks in rural Cameroon, main elements to be considered when dealing with social enterprises in a context of poverty are described and discussed. The BA initiative was thought to leverage data, so as to gain insights supporting factbased decision-making as well as characterize best courses of actions to be undertaken. As intuition can be misleading, many businesses are nowadays increasingly relying on more rigorous analytical analysis to support their organizational decision-making process. Due to the availability of good data, a process orientation, the application of quantitative modeling, and improved software, business analytics focuses on issues that span several organizational functions and address their needs, employs an analytical tool kit, and looks at providing solutions that are embedded into the organizational culture and structure.

More specifically, several challenges and drivers linked to the deployment of a business analytics initiative in a context of poverty have been described in the paper, such as data collection, the culture of the organization, organizational priorities and processes as well as people and technology involved. Based on these considerations, a specific organizational structure has been designed for the network of village banks, based on a research center hosting analytical tools, training of extension service staff acting as liaisons between BA analysts and BA users, and support groups for facilitating the appropriateness of the solution by village bank managers. Then, after identifying areas of needs to be investigated by the BA solution, i.e., information access, insight, and strategic adjustment, and the decision-making process involved by each of them, the most adapted analytical techniques have been selected, mainly based on prescriptive analytics, and implemented 
using synergistically organizational rules and the OR technique called Data Envelopment Analysis or DEA.

Finally, two main elements were found worthy to be considered when working in a context of poverty: the 'behavioral fit' of the business analytics solution to the cultural diversity of the country and a flexible way of being committed to the implementation of the analytics initiative, i.e., the possibility to adapt to feedbacks received in order to adjust prescriptions in a way that considers the 'action-ability' of supports for decision-making provided to organizations. Indeed, deploying a business analytics in an environment of poverty, in a country with a vast diversity of ethnic groups, and in remote locations takes time and most often needs adaptation to local context and customary rules as well as to unexpected events that can temporarily delay implementation.

Getting the capability of modern analytics to discover actionable insights needed by business leaders is a powerful tool, especially in the case of social enterprises that work with a business model containing a social mission to meet basic human needs that are not provided by current economic and social institutions. As they face a double-bottom line, business analytics is of a great interest to monitor their business model, sustain the creation of social values together with economic values, help manage their performance in all its components, identify their core activities on which their sustainability is built upon, and maintain or improve their competitive advantage within their sector or industry.

The BA solution is an on-going experience. The next steps are an adoption and implementation to a large scale within the $\mathrm{MC}^{2}$ network. As analytics are deployed, used, and a greater understanding is gained, we really hope it will contribute to develop microfinance in rural areas and support the fight against poverty of these village banks. Even though numerous additional elements deserve to be investigated, this paper illustrates the possibility to develop a solution helping managers make data-driven decisions, even in a poverty context.

Author Contributions: Conceptualization, I.P.-L. and J.N.; methodology, I.P.-L. and J.N.; software, I.P-L.; formal analysis, I.P.-L.; data curation, J.N.; writing—original draft preparation, I.P.-L.; writingreview and editing, J.N.; project administration, I.P.-L. and J.N. All authors have read and agreed to the published version of the manuscript.

Funding: This research received no external funding.

Institutional Review Board Statement: Not applicable.

Informed Consent Statement: Not applicable.

Data Availability Statement: Data are available at the Microfinance Research Center of the University of Dschang (contact: J. Nzongang, jonzongang@gmail.com).

Acknowledgments: The authors would like to thank the guest editor for his invitation to contribute to this special issue on "The Mediating Role of Environmental, Social, and Governance (ESG) Orientation in Finance and Investments" and for his encouragements and advice throughout the publication process. We are also very grateful to the reviewers for their comments and suggestions.

Conflicts of Interest: The authors declare no conflict of interest.

\section{References}

1. Seelos, C.; Mair, J. Social entrepreneurship: Creating new business models to serve the poor. Bus. Horiz. 2005, 48, 241-246. [CrossRef]

2. Hermes, N.; Lensink, R. The empirics of microfinance: What do we know? Econ. J. 2007, 117, F1-F10. [CrossRef]

3. Yaron, J. What makes rural finance institutions successful? World Bank Res. Obs. 1994, 9, 49-70. [CrossRef]

4. Morduch, J. The Microfinance Schism. World Dev. 2000, 28, 617-629. [CrossRef]

5. Mees, M.; Banda, J. The mutuelles communautaires de croissance ( $\left.\mathrm{MC}^{2}\right)$-Cameroon. Sosfaimzoom Microfinance 2001, 6, 6.

6. World Bank. Poverty \& Equity Brief, Cameroon, Sub-Saharan Africa. 2020. Available online: https://databank.worldbank. org/data/download/poverty/33EF03BB-9722-4AE2-ABC7-AA2972D68AFE/Global_POVEQ_CMR.pdf. (accessed on 12 March 2021). 
7. Piot-Lepetit, I.; Nzongang, J. Financial sustainability and poverty outreach within a network of village banks: A multi-DEA approach. Eur. J. Oper. Res. 2014, 234, 319-330. [CrossRef]

8. Piot-Lepetit, I.; Nzongang, J. Performance assessment and definition of improvement paths for microfinance institutions: An application to a network of village banks in Cameroon. Int. Trans. Oper. Res. 2019, 26, 1188-1210. [CrossRef]

9. Piot-Lepetit, I.; Nzongang, J. Assessing financial and social performance of microfinance institutions over time: The case of MC ${ }^{2}$ network in Cameroon. In Cameroon in the 21st Century: Prospects and Challenges; Environment and People; Piot-Lepetit, I., Ed.; Nova Science Publishers, Inc.: New York, NY, USA, 2017; Volume 2, pp. 253-287.

10. Lustig, I.; Dietrich, B.; Johnson, C.; Dziekan, C. The analytics journey. Bus. Anal. 2010, 11-18. [CrossRef]

11. Mortenson, M.J.; Doherty, N.F.; Robinson, S. Operational research from Taylorism to Terabytes: A research agenda for the analytics age. Eur. J. Operat. Res. 2015, 241, 583-595. [CrossRef]

12. SAS. Assessing Your Business Analytics: Where Do We Go from Here? 2013. Available online: http:/ / www.enterpriseititools. com/sas / Assessing_your_business_analytics_initiatives.pdf (accessed on 7 October 2017).

13. Liberatore, M.J.; Luo, W. The analytics movement: Implication for operations research. Interfaces 2010, 40, 313-324. [CrossRef]

14. Bayrak, T. A review of business analytics: A business enabler or another passing fad. Procedia Soc. Behav. Sci. 2015, 195, 230-239. [CrossRef]

15. Luoma, J. Model-based organizational decision making: A behavioral lens. Eur. J. Oper. Res. 2016, 249, 816-826. [CrossRef]

16. Ranyard, J.C.; Fildes, R.; Hu, T.-I. Reassessing the scope of OR practice: The influences of problem structuring methods and the analytics movement. Eur. J. Oper. Res. 2015, 245, 1-13. [CrossRef]

17. Davenport, H.T. Competing on Analytics. 2006. Available online: https://hbr.org/2006/01/competing-on-analytics (accessed on 5 May 2018).

18. Clark, T.; Wiesenfeld, D. 3 Things are Holding Back your Analytics, and Technology isn't One of Them. 2017. Available online: https:/ / hbr.org/2017/06/3-things-are-holding-back-your-analytics-and-technology-isnt-one-of-them (accessed on 5 May 2018).

19. Nzongang, J.; Kala Kamdjoug, J.R.; Piot-Lepetit, I.; Omenguele, G.R.; Nishimikijimana, E. Efficience des institutions de microfinance: Le cas du réseau des mutuelles communautaires de croissance (MC ${ }^{2}$ ) au Cameroun. Rev. Sci. De Gest. 2010, 77, 93-110.

20. Nzongang, J.; Piot-Lepetit, I.; Kamdem, D. Mesure de l'efficacité financière et sociale d'IMF du réseau MC ${ }^{2}$ au Cameroun par une approche DEA multi-modèles. Mondes En Développement 2012, 160, 99-116. [CrossRef]

21. Hammer, M. Reengineering work: Don't automate, obliterate. Harv. Bus. Rev. 1990, 68, 104-112.

22. Ferdows, K.; DeMeyer, A. Lasting improvements in manufacturing performance: In search of a new theory. J. Oper. Manag. 1990, 9, 168-184. [CrossRef]

23. Zeller, M.; Meyer, R.L. The Triangle of Microfinance: Financial Sustainability, Outreach and Impact; IFPRI-International Food Policy Research Institute, The Johns Hopkins University Press: Baltimore, MD, USA, 2002.

24. Sealey, C.W., Jr.; Lindley, J.T. Inputs, outputs and a theory of production and cost at depository financial institution. J. Financ. 1977, 32, 1251-1266. [CrossRef]

25. Berger, A.N.; DeYoung, R. Problem loans and cost efficiency in commercial banks. J. Bank. Financ. 1997, 21, 849-870. [CrossRef]

26. Hunter, W.C.; Timme, S.G. Core deposits and physical capital: A Reexamination of bank scale economies and efficiency with quasi-fixed inputs. J. Moneycredit Bank. 1995, 28, 165-185. [CrossRef]

27. Banker, R.D.; Chang, H.; Lee, S. Differential impact of Korean banking system reforms on bank productivity. J. Bus. Financ. Account. 2010, 33, 218-235. [CrossRef]

28. DeYoung, R.; Nolle, D. Foreign-owned banks in the US: Earning market share or buying it? J. Moneycredit Bank. 1998, $28,622-636$. [CrossRef]

29. Gutiérrez-Nieto, B.; Serrano-Cinca, C.; Molinero, C.M. Social efficiency in microfinance institutions. J. Oper. Res. Soc. 2009, 60, 104-119. [CrossRef]

30. Basu, A. Five pillars of prescriptive analytics success. Anal. Mag. 2013, 8-12. [CrossRef]

31. Yearworth, M.; Cornell, S.E. Contested modelling: A critical examination of expert modelling in sustainability. Syst. Res. Behav. Sci. 2016, 33, 45-63. [CrossRef]

32. Mingers, J. Soft OR come of age - but not everywhere! Omega 2011, 39, 729-741. [CrossRef]

33. IBM. Analytics: The Real-World Use of Big Data: How Innovative Enterprises Extract Value from Uncertain Data. 2012. Available online: https://www.researchgate.net/publication/315786855_Analytics_the_real-world_use_of_big_data_How_innovative_ enterprises_extract_value_from_uncertain_data_Executive_Report (accessed on 8 September 2017).

34. Donthu, N.; Hershberger, E.K.; Osmonbekov, T. Benchmarking marketing productivity using data envelopment analysis. J. Bus. Res. 2005, 58, 1474-1482. [CrossRef]

35. Spendolini, M. The Benchmarking Book; American Management Association: New York, NY, USA, 1992.

36. Hajalmarsson, L.; Kumbhakar, S.C.; Heshmati, A. DEA, DFA, and SFA: A comparison. J. Product. Anal. 1996, 7, 303-327. [CrossRef]

37. Solórzano-Taborga, P.; Alonso-Conde, A.B.; Rojo-Suárez, J. Data envelopment analysis and multifactor asset pricing models. Int. J. Financ. Stud. 2020, 8, 24. [CrossRef]

38. Babalos, V.; Doumpos, M.; Philippas, N.; Zopounidis, C. Towards a holistic approach for mutual fund performance appraisal. Comput. Econ. 2015, 46, 35-53. [CrossRef] 
39. Zhao, X.; Wang, S.; Lai, K.K. Mutual funds performance evaluation based on endogenous benchmarks. Expert Syst. Appl. 2011, 38, 3663-3670. [CrossRef]

40. Galagedera, D.U.A.; Silvapulle, P. Australian mutual fund performance appraisal using data envelopment analysis. Manag. Financ. 2002, 28, 60-73. [CrossRef]

41. Premachandra, I.M.; Zhu, J.; Watson, J.; Galagedera, D.U.A. Best-performing US Mutual Fund Families from 1993 to 2008 : Evidence from a Novel two-stage DEA model for Efficiency Decomposition. J. Bank. Financ. 2012, 36, 3302-3317. [CrossRef]

42. Eling, M. Performance Measurement of Hedge Funds using Data Envelopment Analysis. Financ. Mark. Porfolio Manag. 2006, 20, 442-471. [CrossRef]

43. Charnes, A.; Cooper, W.W.; Rhodes, E. Measuring the efficiency of decision making units. Eur. J. Oper. Res. 1978, 2, 429-444. [CrossRef]

44. Färe, R.; Grosskopf, S.; Lovell, C.A.K. The Measurement of Efficiency of Production; Springer: Dordrecht, The Netherlands, 1985.

45. Kao, C. Dynamic data envelopment analysis: A relational analysis. Eur. J. Oper. Res. 2013, 227, 325-330. [CrossRef]

46. Schmenner, R.W.; Swink, M.L. On theory in operations management. J. Oper. Manag. 1998, 17, 97-113. [CrossRef]

47. Piot-Lepetit, I. The Theory of Performance Frontiers and Data Envelopment Analysis: Characterizing Performance Improvement Paths; Working Paper; MOISA: Montpellier, France, 2016.

48. CGAP-Consultative Group to Assist the Poorest, The World Bank Group. Microfinance Consensus Guidelines: Definitions of Selected Financial Terms, Ratios and Adjustments for Microfinance, 3rd ed.; GGAP: Washington, DC, USA, 2003.

49. Microrate. Performance Indicators for Microfinance Institutions: Technical Guide, 3rd ed.; Microrate: Arlington, VA, USA, 2003.

50. Woller, G.M. Evaluating MFIs' social performance: A measurement tool. In microNOTE $n^{\circ} 12$ and microREPORT $n^{\circ} 35$; 2006. Available online: https://www.marketlinks.org/resources/evaluating-mfis-social-performance-measurement-tool-micronote (accessed on 5 May 2018).

51. Schreiner, M. Aspects of outreach: A framework for discussion of the social benefits of microfinance. J. Int. Dev. 2002, 14, 591-603. [CrossRef]

52. Piot-Lepetit, I.; Nzongang, J. Assessing the Competitive Advantage of Microfinance Institutions; Working Paper; MOISA: Montpellier, France, 2018.

53. Barlas, Y. Formal aspect of model validity and validation in system dynamics. Syst. Dyn. Rev. 1996, 12, 183-210. [CrossRef]

54. Färe, R.; Grosskopf, S.; Norris, M.; Zhang, Z. Productivity growth, technical progress, and efficiency change in industrialized countries. Am. Econ. Rev. 1994, 84, 66-83.

55. Work Bank. Republic of Cameroon: Priorities for Ending Poverty and Boosting Shared Prosperity. Systematic Country Diagnostic; Work Bank Group: Washington, DC, USA, 2016.

56. Ebongue, A.E. Cameron's official bilingualism: Challenges and perspectives. In Cameroon in the 21st Century: Prospects and Challenges; Environment and People; Piot-Lepetit, I., Ed.; Nova Science Publishers, Inc.: New York, NY, USA, 2017; Volume 2, pp. 315-331.

57. Koa Bessala, P.P.; Ambagna, J.J.; Kane, G.Q. Women land tenure security and agricultural investment in rural Cameroon. In Cameroon in the 21st Century: Prospects and Challenges; Environment and People; Piot-Lepetit, I., Ed.; Nova Science Publishers, Inc.: New York, NY, USA, 2017; Volume 2, pp. 189-217.

58. Ghemawat, P.; del Sol, P. Commitment versus Flexibility? Calif. Manag. Rev. 1998, 40, 26-42. [CrossRef] 